\title{
PTR-TOF-MS and HPLC analysis in the characterization of saffron (Crocus sativus L.) from Italy and Iran
}

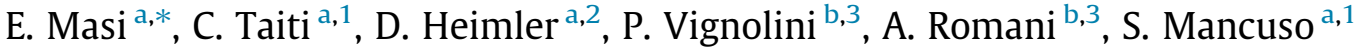 \\ a Dipartimento di Scienze delle Produzioni Agroalimentari e dell'Ambiente (DISPAA), Università di Firenze, P.le delle Cascine 18, 50144 Florence, Italy \\ b Dipartimento di Statistica, Informatica, Applicazioni “G. Parenti” (DISIA), University of Florence, Viale Morgagni 59, 50134 Florence, Italy
}

\section{A R T I C L E I N F O}

\section{Article history:}

Received 20 January 2015

Received in revised form 16 June 2015

Accepted 26 June 2015

Available online 2 July 2015

\section{Keywords:}

Crocus sativus

Saffron

Geographic discrimination

High-performance liquid chromatography

(HPLC)

Proton transfer reaction time-of-flight mass

spectrometer (PTR-TOF-MS)

Volatile organic compounds (VOCs)

\begin{abstract}
A B S T R A C T
Saffron samples from Italy and Iran were analyzed for their content in aroma and bioactive compounds with different analytical techniques. HPLC was used for the identification and quantification of crocins, picrocrocin, safranal and flavonoids content, while the novel proton transfer reaction time-of-flight mass spectrometer was employed for the aroma compounds analysis. Italian saffron turned out to be richer in total crocins and safranal contents. Sample characterization was performed with an unsupervised statistical approach; tests involving different numbers of parameters deriving from the two analytical techniques were performed. The results achieved showed that the best samples classification was obtained by joining the information acquired from both techniques; following such an approach, a sharper separation between Iranian and Italian samples was achieved. Finally, among the variables that most contribute to the description of variability, isophorone, safranal and picrocrocin were identified to be the most significant.
\end{abstract}

(c) 2015 Elsevier Ltd. All rights reserved.

\section{Introduction}

The dried, red stigmas of Crocus sativus L. (saffron) are a very expensive spice known as saffron, which is used as a food flavoring, a coloring agent and as a traditional herbal medicine (Xi \& Qian, 2006). The postharvest dehydration process is necessary to convert C. sativus stigma into the saffron spice.

Iran is the main saffron producer in the world. A few Iranian eastern and south eastern provinces glean the bulk of modern global production. In 2005, the amount of saffron produced in Iran was 230 tons which constituting 93.7\% (82\% being exported) of the world saffron production; the second-ranked Greece produced 5.7 tons $(5700 \mathrm{~kg}$ ), while Morocco and Kashmir, tied for third rank,

\footnotetext{
* Corresponding author at: Dipartimento di Scienze delle Produzioni Agroalimentari e dell'Ambiente (DISPAA), University of Florence, viale delle Idee 30, 50019 Sesto Fiorentino, Florence, Italy.

E-mail addresses: elisa.masi@unfi.it (E. Masi), cosimo.taiti@unfi.it (C. Taiti), daniela.heimler@unifi.it (D. Heimler), Pamela.vignolini@unifi.it (P. Vignolini), annalisa.romani@unifi.it (A. Romani),stefano.mancuso@unifi.it (S. Mancuso).

1 Address: Dipartimento di Scienze delle Produzioni Agroalimentari e dell'Ambiente (DISPAA), University of Florence, viale delle Idee 30, 50019 Sesto Fiorentino, Florence, Italy.

2 Address: Dipartimento di Scienze delle Produzioni Agroalimentari e dell'Ambiente (DISPAA), University of Florence, piazzale delle Cascine 28, 50144 Florence, Italy.

3 Address: Dipartimento di Statistica, Informatica, Applicazioni "G. Parenti", University of Florence, viale Morgagni 65, 50134 Florence, Italy.
}

each produced 2.3 tons $(2300 \mathrm{~kg}$ ) (Ghorbani, 2008). It should be underlined that Iranian saffron is less expensive (it costs up to 5 times less than Italian saffron). Saffron quality is determined by its color, taste, and aroma, which depend on many factors such as soil, climate, rainfall, harvest time, and finally postharvest treatments (Bolandi \& Ghoddusi, 2006; Carmona et al., 2005; Carmona et al., 2007).

The sites of saffron cultivation are often very small and the product that is obtained is related to the peculiar geographic area, therefore the importance of the characterization of this spice must be pointed out (Alonso, Salinas, Garijo, \& Sanchez-Fernandez, 2001; Anastasaki et al., 2009).

The compounds that are responsible of saffron color and taste are crocins, which are glycoside derivatives of crocetin, picrocrocin (mainly responsible for the bitter taste), and safranal (monoterpene aldehyde). Safranal is formed by hydrolysis from picrocrocin during drying and storage (Del Campo et al., 2010; Maggi et al., 2010).

Furthermore, there are compounds that are regarded as pharmacologically active such as crocin derivatives (Li, Lin, Kwan, \& Min, 1999; Rios, Recio, Giner, \& Manez, 1996) and flavonoids. Many papers deal with analytical aspects to set up methods for the separation and determination of the biological active compounds (Alonso et al., 2001; Li et al., 1999; Pfander \& Rychener, 1982; Tarantilis, Polissiou, \& Manfait, 1994; Tarantilis, Tsoupras, 
\& Polissiou, 1995), and aroma components (Carmon et al., 2006; Carmona et al., 2007; D’Auria, Mauriello, Racioppi, \& Rana, 2006; Loskutov, Beninger, Hosfield, \& Sink, 2000; Lozano, Delgado, Gomez, Rubio, \& Iborra, 2000; Tarantilis \& Polissiou, 1997).

The aim of this research is to study both aroma and bioactive compounds in order to improve saffron characterization with the use of techniques such as high-performance liquid chromatography (HPLC) and proton transfer reaction time-of-flight mass spectrometer (PTR-TOF-MS). PTR-TOF-MS is a non-invasive technique which allows the achievement of the whole mass spectra with a time of resolution inferior to $1 \mathrm{~s}$ and the detection of high molecular weight molecules with a high resolution power (Cappellin et al., 2010). Therefore, the PTR-TOF-MS technique, combining high sensitivity, good precision, accuracy and very poor fragmentation of the volatile molecules, can be used for fingerprinting purposes as well as for detailed investigation of single compounds. Indeed, this tool has already been used previously to assess the aromatic profile of various agricultural products, such as apple (Soukoulis et al., 2013), hot pepper (Taiti et al., 2014), olives (Masi, Romani, Pandolfi, Heimler, \& Mancuso, 2014) and tropical fruits (Taiti et al., 2015).

With the two techniques we compared saffron from Gonabad, Torbat and Ghaen (Razavi Khorasan and south Khorazan regions) in Iran and from Città della Pieve, Cascia and Fiesole (Umbria and Tuscany) in Italy.

\section{Materials and methods}

\subsection{Saffron samples}

The analyzed saffron samples were obtained from 6 geographic origins, three in Italy (Fiesole, Cascia, Città della Pieve) and three in Iran (Gonabad, Torbat, Ghaen).

\subsection{HPLC analysis}

Saffron stigmas ( $50 \mathrm{mg}$ ) were extracted with $10 \mathrm{~mL}$ of $70 \%$ ethanol, adjusted to $\mathrm{pH} 2.0$ with formic acid for one night and then filtered to eliminate plant residues.

These extracts were analyzed by HPLC/DAD/MS for the determination of saffron components.

Authentic standard of safranal was purchased from SigmaAldrich (St. Louis, USA), and cinnamic acid, quercitrin and curcumin were purchased from Extrasynthèse S.A. (Lyon, France). All solvents were of HPLC grade purity (BDH Laboratory Supplies, United Kingdom).

Analysis for polyphenols were carried out using a HP 1100L liquid chromatograph equipped with a DAD detector and managed by a HP 9000 workstation (Agilent Technologies, Palo Alto, CA, USA), and were separated by using a $250 \times 4.6 \mathrm{~mm}$ i.d. $5 \mu$ Luna $\mathrm{C} 18 \mathrm{col}-$ umn (Phenomenex) operating at $25^{\circ} \mathrm{C}$. UV/Vis spectra were recorded in the 190-600 $\mathrm{nm}$ range and the chromatograms were acquired at 280, 330, 350 and $440 \mathrm{~nm}$. The mobile phase was a two-steps linear solvent gradient system, starting from $90 \% \mathrm{H}_{2} \mathrm{O}$ (adjusted to $\mathrm{pH} 3.2$ by $\mathrm{HCOOH}$ ) up to $100 \% \mathrm{CH}_{3} \mathrm{CN}$ during a 40 -min period, flow $0.8 \mathrm{~mL} \mathrm{~min}^{-1}$. Quantification of individual compounds was directly performed by HPLC/DAD using a five-point regression curve $\left(r^{2}=0.998\right)$ in the range $0-30 \mathrm{mg}$ on the basis of authentic standards. In particular, crocin derivatives were determined at $440 \mathrm{~nm}$ using curcumin as reference compound. Flavonols were determined at $350 \mathrm{~nm}$ using quercitrin as reference compound, picrocin was determined at $280 \mathrm{~nm}$ using cinnamic acid as reference compound and safranal was determined at $308 \mathrm{~nm}$ using safranal as reference compound. In all cases, actual concentrations of the derivatives were calculated after applying, were possible, corrections for differences in molecular weight. The identity of polyphenols was ascertained using data from HPLC/DAD analyses by comparison and combination of their retention times and UV/Vis spectra with those of authentic standards and previously reported data (Vignolini et al., 2008).

\subsection{PTR-TOF-MS analysis}

Volatile organic compounds (VOCs) emitted from all saffron samples were analyzed with a PTR-TOF-MS 8000 (IoniconAnalytik $\mathrm{GmbH}$, Innsbruck, Austria) using $\mathrm{H}_{3} \mathrm{O}^{+}$as reagent ion for the proton transfer reaction. The reaction takes place between $\mathrm{H}_{3} \mathrm{O}^{+}$ions and all the biogenic or anthropogenic VOCs having a proton affinity higher than that of water $\left(165.2 \mathrm{kcal} \mathrm{mol}^{-1}\right)$. Separation of single ions happens accordingly to their mass to charge $(\mathrm{m} / \mathrm{z})$ ratio. Drift applied voltage was set at $600 \mathrm{~V}$, temperature at $110^{\circ} \mathrm{C}$, pressure $2.25 \mathrm{mbar}$, extraction voltage at the end of the tube $\mathrm{Udx}=32 \mathrm{~V}$; this resulted in a field density ratio $(E / N)$ of about $140 \mathrm{Td}$ ( $E$ being the electric field strength and $N$ the gas number density; $1 \mathrm{Td}=10^{17} \mathrm{~V} \mathrm{~cm}^{2}$ ).

\subsection{Treatment of PTR-TOF-MS samples}

Saffron samples, all previously stored in a cool dark room $\left(15^{\circ} \mathrm{C}\right)$, were brought to room temperature $\left(22-23^{\circ} \mathrm{C}\right)$. For each sample (each analyzed in triplicate), about $1 \mathrm{mg}$ of stigmas were transferred to a glass jar (volume $=10 \mathrm{~mL}$, exposed surface $=6 \mathrm{~cm}^{2}$ ); the jar lid was fitted with Teflon inlet and outlet tubes which were, respectively, connected to a zero-air generator and to the PTR-TOF-MS system. Samples were then equilibrated at $50{ }^{\circ} \mathrm{C}$ in a water bath. The conditions of setup and incubation allowed the formation of a dynamic headspace sampling system with a constant air flow of $0.3 \mathrm{~L} \mathrm{~min}^{-1}$ and a constant humidity, which are critical parameters in for VOCs determination (Mancuso et al., 2015).

The VOCs in the headspace were measured by direct injection into the PTR-TOF drift tube inlet for $120 \mathrm{~s}$. Preliminary measurements on an empty jar were run before every sample measurement and used for background subtraction.

\subsection{PTR-TOF-MS spectra analysis}

Raw data (count rate of the analytes recorded in number of counts per second, cps) were acquired with TofDaq software (Tofwerk AG, Switzerland), using a dead time of $20 \mathrm{~ns}$ for the Poisson correction. In order to guarantee high mass accuracy throughout the analysis study, the mass scale was calibrated following the peaks of known components, present in the spectra at any time $\left(\mathrm{NO}^{+}\right.$peak, $m / z=29.99$, the main isotope of acetone, $\mathrm{C}_{3} \mathrm{H}_{7} \mathrm{O}^{+}, \quad m / z=59.05$, and safranal, $\mathrm{C}_{10} \mathrm{H}_{15} \mathrm{O}^{+}, \quad m / z$ 151.22) (Cappellin et al., 2010). All data from each replicate and background signal were normalized, according to Jardine et al. (2010), by the primary ion signal (cps to $n \mathrm{cps}$ ). For all acquisitions, average spectra considering 50 recorded spectra (corresponding to 50 consecutive seconds of analysis) were obtained and, for a better comparison between samples, data were normalized to sample mass (expressed in grams). Moreover, VOCs were acquired in the range of $m / z=30-250$ using a high mass accuracy for their identification.

\subsection{Statistical data analysis}

Principal component analysis (PCA) was used as unsupervised multivariate technique to represent and explore samples and variables correlations. For the PCA analysis, the average spectra of the three replicates of each saffron sample were used. PCA is a mathematical tool used to reduce the variability of complex data set, generating a relative small number of new descriptors 
(principal components, PCs) accordingly to the correlation between the original variables. Missing data were estimated by using the mean of the corresponding variables. Pearson's correlation coefficient $r$ as a statistical measure of the strength of a linear relationship between paired variables was also calculated. The same coefficient was used to perform hierarchical cluster analysis in order to group samples with similarities and mean linkage clustering was used to draw a dendrogram. The software used to perform statistical analysis was Addinsoft XLSTAT (Ver. 2014.2.04).

\section{Results and discussion}

\subsection{HPLC analysis}

The first datum that should be taken into account is the significantly higher $(p<0.05)$ total crocins content in Italian samples with respect to Iranian ones (Table 1 ). The crocins, a family of red-colored and water-soluble carotenoids, are glycosyl esters of crocetin with different sugar moieties, such as glucose, gentiobiose, neapolitanose or triglucose; they can be present in saffron in cis and trans isomeric forms. Total crocins content of Italian samples is generally higher than the values reported for Moroccan saffron samples (Lage \& Cantrell, 2009). The most abundant compounds were trans-crocin 4 and trans-crocin 3, with a significant difference $(p<0.05)$ between Italian and Iranian origins. Both compounds accounted for $91 \%$ of total crocins content in the case of Italian samples and for $78 \%$ in the case of Iranian ones. These two compounds have been already described, in a study on saffron from 10 different countries (Caballero-Ortega, Pereda-Miranda, \& Abdullaev, 2007), as the most abundant, even if quantitative data could not be compared since these data were reported as $\mathrm{mg} / \mathrm{g}$ of stigmas. Cis-crocin 4 and trans-crocin 2 contents were higher in Iranian than in Italian samples $(p<0.05)$. Concerning safranal, its content was significantly $(p<0.05)$ more abundant in Italian provenances. No picrocrocin and 2,6,6-trimethyl-4-hydroxy-1-car boxaldehyde-1-cyclohexene (HTCC) were found; saffron dehydration process involves the formation of safranal from HTTC and picrocrocin (Boschetti et al., 1999).

As regards flavonoids, three kaempferol derivatives were identified according to previous findings (Carmona et al., 2007; Vignolini et al., 2008), and one compound, also a kaempferol derivative, has not been characterized. Significant differences $(p<0.05)$ have been found only in the case of kaempferol-3-sophor iside-7-glucoside. Among Italian samples both crocins and flavonoids contents were highest in the Fiesole provenance and, in the case of Iranian samples, the Torbat provenance showed the highest crocins content.

\subsection{PTR-TOF-MS analysis}

Table 2 shows all masses highlighted by PTR-TOF-MS analysis present in the six saffron samples, and their possible identification, taking into account the available fragmentation patterns of pure standards (Diskin, Wang, Smith, \& Španěl, 2002; Fujii, Selvin, Sablier, \& Iwase, 2001; Lozano, Castellar, Simancas, \& Iborra, 1999; Mayr, Märk, Lindinger, Brevard, \& Yeretzian, 2003; Wang, Španěl, \& Smith, 2004). All masses listed have already been identified in saffron stigmas. An equal number to any possible compound having the same protonated theoretical mass was attributed. In

Table 1

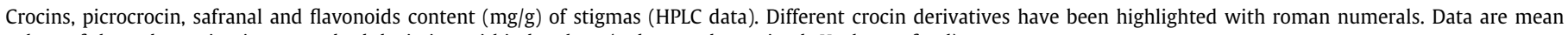
values of three determinations, standard deviation within brackets (n.d. = not determined; $\mathrm{K}=$ kaempferol).

\begin{tabular}{|c|c|c|c|c|c|c|c|}
\hline & \multirow[t]{2}{*}{ Compound } & \multicolumn{3}{|l|}{ Iran } & \multicolumn{3}{|l|}{ Italy } \\
\hline & & Gonabad & Torbat & Ghaen & Città della Pieve & Cascia & Fiesole \\
\hline \multicolumn{8}{|c|}{ Crocins } \\
\hline $\mathrm{H} 1$ & trans-Crocin 5 & $1.63(0.049)$ & $1.98(0.098)$ & $1.61(0.061)$ & $1.13(0.031)$ & $1.14(0.054)$ & $1.52(0.044)$ \\
\hline $\mathrm{H} 2$ & Crocin derivative I & $1.05(0.097)$ & $1.67(0.108)$ & $1.30(0.112)$ & $2.22(0.113)$ & $2.62(0.080)$ & $2.72(0.053)$ \\
\hline H3 & Crocin derivative II & $0.66(0.035)$ & $0.51(0.059)$ & $0.65(0.034)$ & $0.45(0.028)$ & $0.41(0.048)$ & $0.49(0.013)$ \\
\hline $\mathrm{H} 4$ & Crocin derivative III & $0.92(0.031)$ & $0.90(0.026)$ & $1.17(0.035)$ & $1.16(0.018)$ & $1.50(0.062)$ & $1.58(0.023)$ \\
\hline H5 & Crocin derivative IV & $0.53(0.062)$ & $0.51(0.049)$ & $0.52(0.019)$ & $0.35(0.031)$ & $0.22(0.021)$ & $0.51(0.005)$ \\
\hline H6 & trans-Crocin 4 & $168.91(1.356)$ & $238.02(0.964)$ & $197.80(0.897)$ & $302.65(1.974)$ & $343.97(1.957)$ & $372.49(0.681)$ \\
\hline $\mathrm{H} 7$ & Crocin derivative I & $1.32(0.009)$ & $2.18(0.012)$ & $1.69(0.036)$ & $2.71(0.022)$ & $2.66(0.134)$ & $2.75(0.014)$ \\
\hline H8 & Crocin derivative II & $1.19(0.035)$ & $2.44(0.056)$ & $1.30(0.028)$ & $0.98(0.052)$ & $1.01(0.041)$ & $1.03(0.0392)$ \\
\hline H9 & trans-Crocin 3 & $61.25(0.485)$ & $85.36(0.531)$ & $71.56(0.68)$ & $109.17(0.605)$ & $111.94(0.893)$ & $123.15(1.0407)$ \\
\hline $\mathrm{H} 10$ & Crocin derivative I & $0.40(0.027)$ & $0.51(0.021)$ & $0.39(0.035)$ & $0.66(0.013)$ & $0.58(0.040)$ & $0.67(0.029)$ \\
\hline H11 & Crocin derivative II & $1.71(0.012)$ & $1.41(0.010)$ & $1.64(0.028)$ & $1.37(0.018)$ & $1.43(0.141)$ & $0.71(0.011)$ \\
\hline H12 & trans-Crocin $2^{\prime}$ & $1.64(0.091)$ & $3.63(0.158)$ & $2.53(0.164)$ & $3.29(0.146)$ & $2.81(0.173)$ & $1.23(0.012)$ \\
\hline $\mathrm{H} 13$ & Crocin derivative I & $0.53(0.035)$ & $0.51(0.049)$ & $0.52(0.041)$ & $0.41(0.033)$ & $0.37(0.048)$ & $2.38(0.0437)$ \\
\hline $\mathrm{H} 14$ & Crocin derivative II & $0.13(0.015)$ & $0.26(0.020)$ & $0.26(0.012)$ & $0.55(0.051)$ & $0.71(0.059)$ & $0.47(0.012)$ \\
\hline H15 & Crocin derivative III & n.d. & n.d. & n.d. & n.d. & $0.32(0.042)$ & $0.51(0.012)$ \\
\hline H16 & Crocin derivative IV & n.d. & n.d. & n.d. & n.d. & n.d. & $0.24(0.015)$ \\
\hline $\mathrm{H} 17$ & cis-Crocin 4 & $30.42(1.521)$ & $19.38(0.851)$ & $26.88(0.862)$ & $5.73(0.053)$ & $7.37(0.390)$ & $12.55(0.606)$ \\
\hline H18 & Crocin derivative I & $0.79(0.061)$ & $0.77(0.072)$ & $0.65(0.048)$ & $0.41(0.034)$ & $0.51(0.058)$ & $0.62(0.013)$ \\
\hline H19 & Crocin derivative II & $0.53(0.026)$ & $0.38(0.027)$ & $0.52(0.049)$ & $0.30(0.022)$ & $0.44(0.057)$ & $0.38(0.009)$ \\
\hline $\mathrm{H} 20$ & trans-Crocin 2 & $26.00(0.58)$ & $24.30(0.69)$ & $24.86(0.41)$ & $16.12(0.352)$ & $13.59(0.172)$ & $21.24(0.457)$ \\
\hline $\mathrm{H} 21$ & Crocin derivative I & $0.40(0.024)$ & $0.38(0.018)$ & $0.39(0.011)$ & n.d. & n.d. & n.d. \\
\hline $\mathrm{H} 22$ & cis-Crocin 1 & $1.58(0.087)$ & $2.22(0.091)$ & $1.73(0.103)$ & $1.06(0.090)$ & $0.81(0.077)$ & $1.48(0.032)$ \\
\hline $\mathrm{H} 23$ & Crocin derivative I & $0.53(0.048)$ & $0.51(0.039)$ & $0.52(0.061)$ & n.d. & n.d. & n.d. \\
\hline $\mathrm{H} 24$ & Crocin derivative II & $0.40(0.022)$ & $0.38(0.035)$ & $0.39(0.029)$ & n.d. & n.d. & $0.12(0.011)$ \\
\hline $\mathrm{H} 25$ & Total & 302.51 & 388.23 & 338.87 & 450.73 & 494.42 & 548.84 \\
\hline $\mathrm{H} 26$ & Picrocrocin & $36.97(0.031)$ & $67.95(0.025)$ & $43.82(0.029)$ & $101.92(0.783)$ & $127.83(0.881)$ & $130.35(1.026)$ \\
\hline $\mathrm{H} 27$ & Safranal & $1.26(0.091)$ & $1.79(0.126)$ & $1.35(0.108)$ & $2.41(0.103)$ & $3.01(0.298)$ & $2.01(0.134)$ \\
\hline \multicolumn{8}{|c|}{ Flavonoids } \\
\hline $\mathrm{H} 28$ & K-3-sophoroside-7-glucoside & $2.64(0.015)$ & $2.95(0.022)$ & $2.99(0.030)$ & $4.89(0.026)$ & $4.17(0.080)$ & $5.18(0.038)$ \\
\hline $\mathrm{H} 29$ & $\mathrm{~K}$ derivative & $1.05(0.041)$ & $0.90(0.029)$ & $1.30(0.022)$ & $1.07(0.040)$ & $1.24(0.038)$ & $1.35(0.043)$ \\
\hline H30 & $\mathrm{K}-3,7,4^{\prime}$-triglucoside & $2.51(0.015)$ & $2.95(0.016)$ & $2.21(0.027)$ & n.d. & n.d. & $1.53(0.039)$ \\
\hline H31 & K-3-sophoroside & $10.02(0.064)$ & $10.38(0.061)$ & $8.83(0.068)$ & $8.39(0.059)$ & $5.11(0.063)$ & $9.61(0.087)$ \\
\hline H32 & Total & 16.22 & 17.18 & 15.33 & 14.35 & 10.52 & 17.67 \\
\hline
\end{tabular}


two cases (P11 and P17), different protonated theoretical masses of putative compounds have been associated: in both cases, the system detects only one peak due to the small differences in their $m / z$. Other masses that were expected to be found were not actually present in the saffron samples studied. Interestingly, mass identified as 4-hydroxy-2,6,6-trimethyl-1-cyclohexen-1-carboxal dehyde (HTCC), the aglycone precursor of safranal, was not present in any of the samples, indicating quality in the transformation (dehydration) process, thus confirming the data from HPLC. Furthermore, only five fragments have been detected (Tarantilis \& Polissiou, 1997), according to the low fragmentation characteristic of the PTR-TOF-MS analysis.
With regard to the content of safranal in the samples, the PTR-TOF-MS approach also underlined great differences between saffron from different geographic origins. Two samples from Italy (Cascia and Città della Pieve) showed to be the richest; two from Iran (Ghaen and Gonabad) had the lowest amount of safranal, while the saffron from Fiesole (Italy) and that from Torbat (Iran) had intermediate amounts (see Fig. 1).

\subsection{Principal component analysis on PTR-TOF-MS data}

The analysis performed on the PTR-TOF-MS mass spectra of the headspace of the six saffron under study allowed the compilation

Table 2

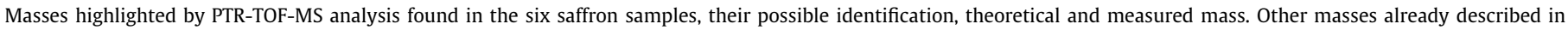
saffron, but not detected by PTR-TOF-MS analysis in this study are also listed (marked with an asterisk).

\begin{tabular}{|c|c|c|c|c|c|}
\hline & \multirow[t]{2}{*}{ Compound } & \multirow[t]{2}{*}{ Protonated formula } & \multicolumn{2}{|c|}{ Protonated mass $(M / Z)$} & \multirow[t]{2}{*}{ Refs. } \\
\hline & & & Theor. & Meas. & \\
\hline P1 & Acetic acid & $\mathrm{C}_{2} \mathrm{H}_{5} \mathrm{O}_{2}^{+}$ & 61.05 & 61.03 & 4,5 \\
\hline P2 & 2(5H)-furanone & $\mathrm{C}_{4} \mathrm{H}_{5} \mathrm{O}_{2}^{+}$ & 85.07 & 85.03 & 2,5 \\
\hline P3 & 3-Methylbutanal & $\mathrm{C}_{5} \mathrm{H}_{11} \mathrm{O}^{+}$ & 87.13 & 87.08 & 2,5 \\
\hline P3 & 2-Methylbutanal & $\mathrm{C}_{5} \mathrm{H}_{11} \mathrm{O}^{+}$ & 87.13 & 87.08 & 2,5 \\
\hline P4 & 1-Pentanol & $\mathrm{C}_{5} \mathrm{H}_{13} \mathrm{O}^{+}$ & 89.15 & 89.10 & 2,5 \\
\hline P5 & Phenol & $\mathrm{C}_{6} \mathrm{H}_{7} \mathrm{O}^{+}$ & 95.06 & 95.05 & 6 \\
\hline P6 & Hexanal & $\mathrm{C}_{6} \mathrm{H}_{13} \mathrm{O}^{+}$ & 101.16 & 101.10 & 2,5 \\
\hline P7 & Benzaldehyde & $\mathrm{C}_{7} \mathrm{H}_{7} \mathrm{O}^{+}$ & 107.12 & 107.05 & 2 \\
\hline P8 & 1,1,3-Trimethylcyclopentadiene & $\mathrm{C}_{8} \mathrm{H}_{13}^{+}$ & 109.18 & 109.10 & 2 \\
\hline P9 & 2,5-Dimethyl-2,4-hexadiene & $\mathrm{C}_{8} \mathrm{H}_{15}^{+}$ & 111.20 & 111.11 & 2,5 \\
\hline * & Heptanal & $\mathrm{C}_{7} \mathrm{H}_{15} \mathrm{O}^{+}$ & 115.19 & & 2,5 \\
\hline P10 & 1,3,5-Trimethylbenzene & $\mathrm{C}_{9} \mathrm{H}_{13}^{+}$ & 121.19 & 121.10 & 2,5 \\
\hline P11 & 2-Phenylethanol & $\mathrm{C}_{8} \mathrm{H}_{11} \mathrm{O}^{+}$ & 123.16 & 123.08 & $2,3,5$ \\
\hline P11 & 1-t-Butylcyclopentadiene & $\mathrm{C}_{9} \mathrm{H}_{15}^{+}$ & 123.21 & 123.12 & 2,5 \\
\hline P12 & 6-Methyl-3,5-heptadien-2-one & $\mathrm{C}_{8} \mathrm{H}_{13} \mathrm{O}^{+}$ & 125.18 & 125.10 & 2,5 \\
\hline P13 & 2-Hydroxy-5-cyclohexen-1,4-dione & $\mathrm{C}_{6} \mathrm{H}_{7} \mathrm{O}_{3}^{+}$ & 127.11 & 127.04 & 3 \\
\hline P14 & 6-Methyl-5-hepten-2-one & $\mathrm{C}_{8} \mathrm{H}_{15} \mathrm{O}^{+}$ & 127.19 & 127.11 & 2,5 \\
\hline P15 & Octanal & $\mathrm{C}_{8} \mathrm{H}_{17} \mathrm{O}^{+}$ & 129.21 & 129.13 & 2,5 \\
\hline P16 & $\beta$-Phellandrene & $\mathrm{C}_{10} \mathrm{H}_{17} \mathrm{O}^{+}$ & 137.24 & 137.13 & 2,5 \\
\hline P17 & 5,5-Dimethyl-2-cyclohexen-1,4-dione & $\mathrm{C}_{8} \mathrm{H}_{11} \mathrm{O}_{2}^{+}$ & 139.16 & 139.08 & 2,5 \\
\hline P17 & 3,5,5-Trimethyl-3-cyclohexen-1-one & $\mathrm{C}_{9} \mathrm{H}_{15} \mathrm{O}^{+}$ & 139.21 & 139.11 & 3,5 \\
\hline P17 & 3,5,5-Trimethyl-2-cyclohexen-1-one (isophorone) & $\mathrm{C}_{9} \mathrm{H}_{15} \mathrm{O}^{+}$ & 139.21 & 139.11 & $1,3-5$ \\
\hline P17 & 3,5,5-Trimethylcyclohex-3-en-1-one & $\mathrm{C}_{9} \mathrm{H}_{15} \mathrm{O}^{+}$ & 139.21 & 139.11 & 2,5 \\
\hline P17 & 3,5,5-Trimethylcyclohexenone & $\mathrm{C}_{9} \mathrm{H}_{15} \mathrm{O}^{+}$ & 139.21 & 139.11 & 5 \\
\hline P17 & 3,7-Dimethyl-1,6-octadiene & $\mathrm{C}_{10} \mathrm{H}_{19}^{+}$ & 139.21 & 139.15 & 3 \\
\hline * & Nonanal & $\mathrm{C}_{9} \mathrm{H}_{19} \mathrm{O}^{+}$ & 143.24 & & 2,5 \\
\hline P18 & 4-(1-Methylethyl)-benzaldehyde & $\mathrm{C}_{10} \mathrm{H}_{13} \mathrm{O}^{+}$ & 149.20 & 149.10 & 2,5 \\
\hline P18 & 2,4,5-Trimethylbenzaldehyde & $\mathrm{C}_{10} \mathrm{H}_{13} \mathrm{O}^{+}$ & 149.20 & 149.10 & 2,5 \\
\hline P19 & 2,6,6-Trimethyl-1,4-cyclohexadien-1-carboxaldehyde & $\mathrm{C}_{10} \mathrm{H}_{15} \mathrm{O}^{+}$ & 151.22 & 151.11 & 3,5 \\
\hline P19 & 2,6,6-Trimethyl-1,3-cyclohexadien-1-carboxaldehyde (safranal) & $\mathrm{C}_{10} \mathrm{H}_{15} \mathrm{O}^{+}$ & 151.22 & 151.11 & $2-5$ \\
\hline P19 & 4-Methylene-3,5,5-trimethyl-2-cyclohexen-1-one & $\mathrm{C}_{10} \mathrm{H}_{15} \mathrm{O}^{+}$ & 151.22 & 151.11 & 3 \\
\hline P19 & 4,6,6-Trimethyldicyclo-[3.1.1]hept-3-en-2-one & $\mathrm{C}_{10} \mathrm{H}_{15} \mathrm{O}^{+}$ & 151.22 & 151.11 & 3 \\
\hline P20 & 2-Hydroxy-2,6,6-trimethyl-2-cyclohexen1,4-dione & $\mathrm{C}_{9} \mathrm{H}_{13} \mathrm{O}_{2}^{+}$ & 153.19 & 153.09 & $1-4$ \\
\hline P20 & 2-Hydroxy-4,4,6-trimethyl-2,5-cyclohexadien-1-one & $\mathrm{C}_{9} \mathrm{H}_{13} \mathrm{O}_{2}^{+}$ & 153.19 & 153.09 & $1-4$ \\
\hline P20 & 3,5,5-Trimethylcyclohex-2-en-1,4-dione & $\mathrm{C}_{9} \mathrm{H}_{13} \mathrm{O}_{2}^{+}$ & 153.19 & 153.09 & 5 \\
\hline P21 & 3,7-Dimethyl-1,6-octadien-3-ol (linalool) & $\mathrm{C}_{10} \mathrm{H}_{19} \mathrm{O}^{+}$ & 155.15 & 155.14 & 3 \\
\hline P22 & 2,2-Dimethyl-4-oxocyclohexan-1-carboxaldehyde & $\mathrm{C}_{9} \mathrm{H}_{15} \mathrm{O}_{2}^{+}$ & 155.21 & 155.11 & 3 \\
\hline P22 & 2,6,6-Trimethylcyclohexan-1,4-dione & $\mathrm{C}_{9} \mathrm{H}_{15} \mathrm{O}_{2}^{+}$ & 155.21 & 155.11 & $1-3$ \\
\hline P22 & 4-Hydroxy-3,5,5-trimethyl-2-cyclohexen-1-one & $\mathrm{C}_{9} \mathrm{H}_{15} \mathrm{O}_{2}^{+}$ & 155.21 & 155.11 & 4 \\
\hline P22 & 2,6,6-Trimethyl-1,4-cyclohexanedione & $\mathrm{C}_{9} \mathrm{H}_{15} \mathrm{O}_{2}^{+}$ & 155.21 & 155.11 & 1 \\
\hline P22 & 3,5,5-Trimethylcyclohexan-1,4-dione (2-hydroxyisophorone) & $\mathrm{C}_{9} \mathrm{H}_{15} \mathrm{O}_{2}^{+}$ & 155.21 & 155.11 & 5 \\
\hline P23 & 3,3,4,5-Tetramethylcyclohexan-1-one & $\mathrm{C}_{10} \mathrm{H}_{19} \mathrm{O}^{+}$ & 155.25 & 155.14 & 3 \\
\hline P24 & 2,6,6-Trimethyl-3-oxo-1-cyclohexen-1-carboxaldehyde & $\mathrm{C}_{10} \mathrm{H}_{15} \mathrm{O}_{2}^{+}$ & 167.22 & 167.10 & 3 \\
\hline * & 4-Hydroxy-2,6,6-trimethyl-1-cyclohexen-1-carboxaldehyde (HTCC) & $\mathrm{C}_{10} \mathrm{H}_{17} \mathrm{O}_{2}^{+}$ & 169.27 & & 1 \\
\hline P25 & 4-Hydroxy-2,6,6-trimethyl-3-oxo-cyclohexan-1-carboxaldehyde & $\mathrm{C}_{10} \mathrm{H}_{13} \mathrm{O}_{3}^{+}$ & 181.20 & 181.09 & 1,3 \\
\hline * & 4-Hydroxy-2,6,6-trimethyl-3-oxo-1,4-cyclohexadien-1-carboxaldehyde & $\mathrm{C}_{10} \mathrm{H}_{17} \mathrm{O}_{3}^{+}$ & 185.27 & & 3 \\
\hline P26 & 4-(2,6,6,-Trimethyl-1-cyclohexen-1-yl)-3-buten-2-one & $\mathrm{C}_{13} \mathrm{H}_{21} \mathrm{O}^{+}$ & 193.30 & 193.16 & 3 \\
\hline P26 & $\beta$-Ionone & $\mathrm{C}_{13} \mathrm{H}_{21} \mathrm{O}^{+}$ & 193.30 & 193.16 & 2,5 \\
\hline P27 & 4-(2,2,6,-Trimethyl-cyclohexan-1-yl)-3-buten-2-one & $\mathrm{C}_{13} \mathrm{H}_{27} \mathrm{O}^{+}$ & 195.31 & 195.17 & 3 \\
\hline P27 & Dihydro- $\beta$-ionone & $\mathrm{C}_{13} \mathrm{H}_{27} \mathrm{O}^{+}$ & 195.31 & 195.17 & 2,5 \\
\hline P27 & (E)-6,10-Dimethyl-5,9-undecadien-2-one & $\mathrm{C}_{13} \mathrm{H}_{27} \mathrm{O}^{+}$ & 195.31 & 195.17 & 2,5 \\
\hline P28 & Dihydro- $\beta$-ionol & $\mathrm{C}_{13} \mathrm{H}_{25} \mathrm{O}^{+}$ & 197.33 & 197.19 & 2,5 \\
\hline * & 2,6-di-(1,1-Dimethylethyl)-phenol & $\mathrm{C}_{14} \mathrm{H}_{27} \mathrm{O}^{+}$ & 207.14 & & 2,5 \\
\hline * & 2,4,4-Trimethyl-3-(3-oxo-1-butenyl)-2-cyclohexen-1-ol & $\mathrm{C}_{13} \mathrm{H}_{21} \mathrm{O}_{2}^{+}$ & 209.15 & & 3 \\
\hline
\end{tabular}

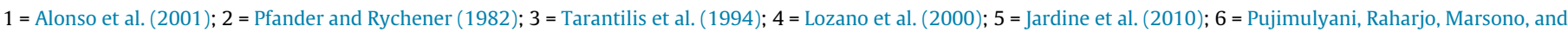
Santoso (2013). 


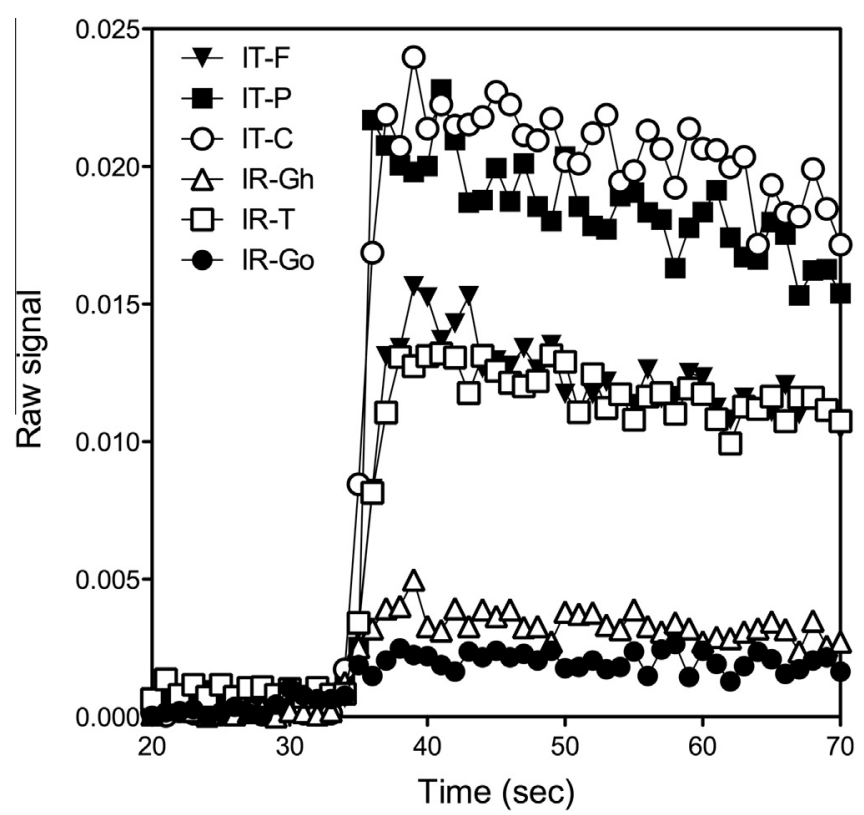

Fig. 1. Signal intensity (ncps) of the putative mass safranal (mass P19) in the 6 saffron samples. of a table of 28 mass peaks (masses with intensity equal to zero $n c p s$ in all the samples were ignored).

The first two components obtained with PCA explained more than $75 \%$ of the total variability and the deriving two-dimensional scatter plot provided the main separation of saffron from Cascia (IT-C) and Città della Pieve (IT-P), showing them to be clearly separated from each other and from the rest of the samples (Fig. 2, top left). Saffron from Iran and the Italian one from Fiesole shared almost the same region of the plot, mainly in the negative range of both PCs; nevertheless, each group of replicates of the same geographic origin appeared quite distinct, especially those from Fiesole that occupied also the positive range of the PC1.

Further interesting information could be achieved from the analysis of the contribution of each original variable to the new ones generated with the PCA (Table 3, case "A"). For example, the mass tentatively identified as isophorone (P17) was one with the bigger role in the definition of the first component, that described $46.21 \%$ of total variability. This occurrence has already pointed out in saffron from Tuscan Maremma (Macchia, Ceccarini, Molfetta, Cioni, \& Flamini, 2013). Isophorone is characterized by floral notes. This is in contrast with safranal, that confers to saffron its spicy characteristic aromatic notes (Maggi et al., 2009). Isophorone was abundant in saffron from Città della Pieve (IT-P), whose position in the bi-factors plot is in the positive range of PC1 (Fig. 2, top left). Concerning the second principal component (PC2), the compounds that mainly participate to its definition are
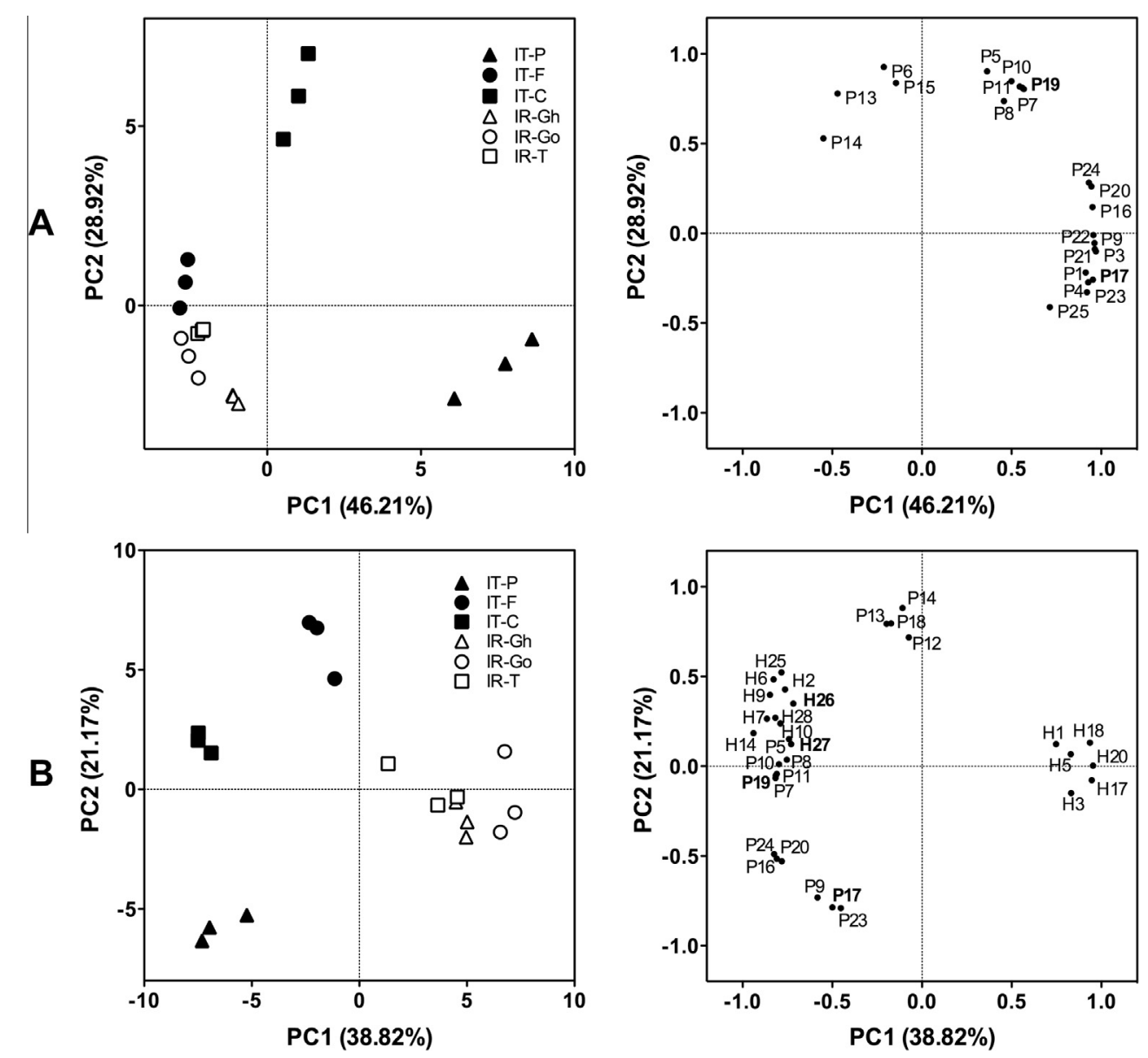

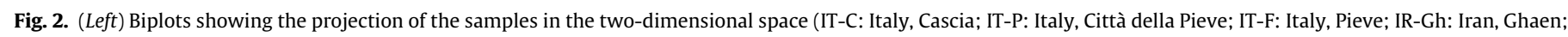

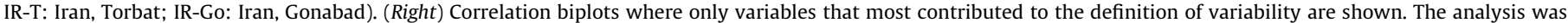

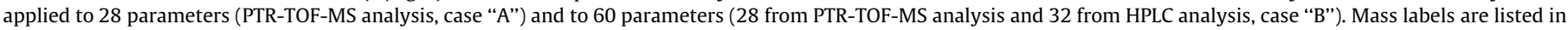
Tables 1 and 2; P, obtained with PTR-TOF-MS analyses; H, obtained with HPLC analyses; in bold character the most interesting variables are underlined. 
mostly present in Cascia samples (IT-C), that are in the positive range of this PC. The compound tentatively identified as safranal was one of these. The compound 2(H5)-furanone (P2), known as a useful compound for fingerprinting Iranian saffron (Jalali-Heravi, Parastar, \& Ebrahimi-Najafabadi, 2010; Maggi et al., 2009), did not have a significant role in the definition of the samples variability.

As underlined in the correlation plot (Fig. 2, top right), that shows a projection of the initial variables in the PC space, most of the variables were positioned in the positive range of PC1 and PC2, showing significant correlations $(p<0.05)$. For example, the compound tentatively identified as safranal (P19) showed to be strongly correlated with compounds identified as phenol (P5, $r=0.971$ ), benzaldehyde (P7, $r=0.999), 1,3,5$-trimethylbenzene (P10, $r=0.994)$, and 1-t-butylcyclopentadiene (P11, $r=1.000)$. The other interesting compound in saffron studies, isophorone, here identified as P17, was positively and significatively correlated with the following compounds: P1 $(r=0.946)$, P3 $(r=0.961)$, P4 $(r=0.969), \mathrm{P} 9(r=0.903), \mathrm{P} 21(r=0.947), \mathrm{P} 22(r=0.940)$ and P23 $(r=0.976)$. Negative correlations, when present, were not significant.

To conclude, PCA on PTR-TOF-MS parameters showed that saffron from Fiesole (IT-F) appeared to share more analogies with

\section{Table 3}

Variables that most contribute to the description of samples variability as underlined by principal component analysis (PCA). The analysis was applied to 28 parameters (PTR-TOF-MS analysis, case "A") and to 60 parameters (28 from PTR-TOF-MS analysis and 32 from HPLC analysis, case "B"). Here we select all the variables with highest influence for the first two components (PC1 and PC2), namely with squared cosine bigger than 0.5 .

\begin{tabular}{|c|c|c|c|c|}
\hline \multirow[t]{2}{*}{ Compound } & \multicolumn{2}{|l|}{ Case "A" } & \multicolumn{2}{|l|}{ Case "B" } \\
\hline & PC1 (\%) & PC2 (\%) & PC1 (\%) & PC2 (\%) \\
\hline P1 & 6.46 & & & \\
\hline P3 & 7.29 & & & \\
\hline P4 & 6.66 & & & \\
\hline P5 & & 10.08 & 2.29 & \\
\hline P6 & & 10.64 & & \\
\hline P7 & & 8.13 & 2.86 & \\
\hline P8 & & 6.73 & 2.44 & \\
\hline P9 & 7.08 & & & 4.22 \\
\hline P10 & & 8.88 & 2.74 & \\
\hline P11 & & 8.28 & 2.82 & \\
\hline P12 & & & & 4.06 \\
\hline P13 & & 7.50 & & 4.97 \\
\hline P14 & & & & 6.13 \\
\hline P15 & & 8.70 & & \\
\hline P16 & 7.00 & & 2.63 & \\
\hline P17 & 7.02 & & & 4.88 \\
\hline P18 & & & & 4.97 \\
\hline P19 & & 7.98 & 2.86 & \\
\hline P20 & 6.91 & & 2.82 & \\
\hline P21 & 7.19 & & 1.88 & \\
\hline P22 & 7.15 & & 2.04 & \\
\hline P23 & 6.56 & & & 4.92 \\
\hline P24 & 6.72 & & 2.92 & \\
\hline P25 & 3.93 & & & \\
\hline $\mathrm{H} 1$ & & & 2.39 & \\
\hline $\mathrm{H} 2$ & & & 2.50 & \\
\hline H3 & & & 2.97 & \\
\hline H5 & & & 2.96 & \\
\hline H6 & & & 2.94 & \\
\hline H7 & & & 3.21 & \\
\hline H9 & & & 3.08 & \\
\hline $\mathrm{H} 10$ & & & 2.68 & \\
\hline $\mathrm{H} 14$ & & & 3.79 & \\
\hline $\mathrm{H} 17$ & & & 3.85 & \\
\hline H18 & & & 3.77 & \\
\hline $\mathrm{H} 2 \mathrm{O}$ & & & 3.90 & \\
\hline $\mathrm{H} 25$ & & & 2.64 & \\
\hline $\mathrm{H} 26$ & & & 2.21 & \\
\hline $\mathrm{H} 27$ & & & 2.36 & \\
\hline $\mathrm{H} 28$ & & & 2.87 & \\
\hline
\end{tabular}

saffron aromatic profile from Iran than with those from the same country, and that isophorone and safranal were the most useful compounds to describe samples variability.

\subsection{Principal component analysis on PTR-TOF-MS data and HPLC data}

PCA performed on the 60 variables showed in Tables 1 and 2 (obtained with PTR-TOF-MS and HPLC analysis, respectively) explained about $60 \%$ of total variability by mean of the first two PCs. The two-dimensional scatter plot (Fig. 2, bottom left) underlined a clear separation of the three Italian saffron samples in regard to each other and to the saffron from Iran. The main separation was achieved between the samples from Italy; in details, the three saffron shared the negative range of the PC1, with saffron from Città della Pieve (IT-P) and that from Cascia (IT-C) and Fiesole (IT-F) occupying respectively the negative and the positive range of the $\mathrm{PC} 2$. Iranian samples were positioned in the positive range of $\mathrm{PC} 1$, quite close one to each other.

Most of the original variables contributed to the first PC, that described $38.82 \%$ of variability; among those obtained with HPLC analysis, it is worth noting the contribution of picrocrocin (H26) and safranal (H27). Interestingly, also the compound detected using PTR-TOF-MS technique and identified as safranal (P19) had a significant role in the definition of the first component. On the other hand, the compound identified as isophorone (P17) was determinant for the definition of PC2.

The correlation plot (Fig. 2, bottom right) confirmed the correlation underlined in case " $A$ ". No significant positive correlations were found between variables deriving from the two different analytical approaches, while most of the variables obtained with PTR-TOF-MS analysis showed negative correlation with many HPLC parameters. Furthermore, safranal content (H27) was not significantly correlated with other HPLC parameters, except for the case of picrocrocin $(\mathrm{H} 26, r=0.887)$. The latter, instead, showed positive correlation with trans-crocin $4(\mathrm{H} 6, r=0.814)$, and tran$s$-crocin 3 (H9, $r=0.830$ ).

Pooling all dataset, derived from PTR-TOF-MS analysis and that obtained with HPLC analysis, the difference of saffron from Iran in respect to the Italian ones was explained; more information on the samples from Fiesole (Italy), that was here better distinct from the rest of the Iranian samples, was achieved. Furthermore, key compounds detected with PTR-TOF-MS analysis (identified as safranal and isophorone) confirmed to be useful for the characterization of samples; similar consideration could be done concerning safranal and picrocrocin data obtained with HPLC analysis.

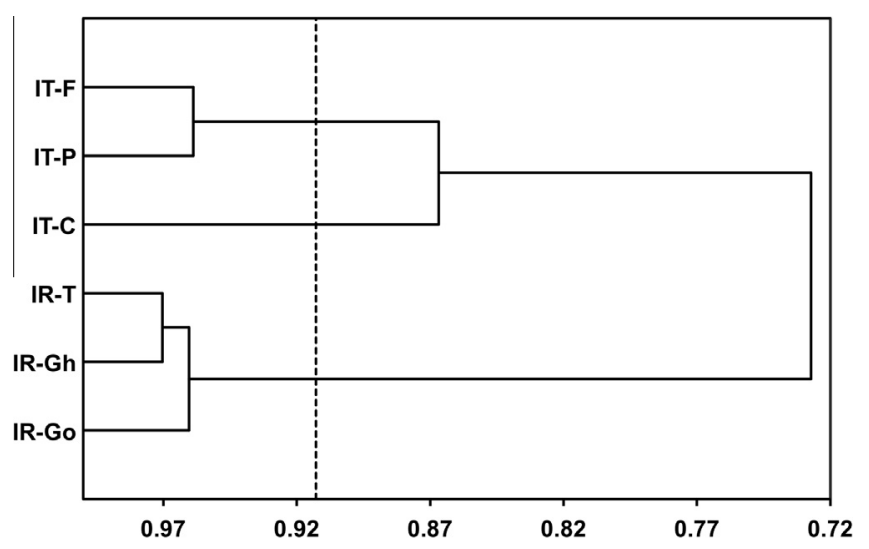

Fig. 3. Hierarchical cluster analysis dendrogram obtained analysing 60 variables (from HPLC and PTR-TOF-MS investigation); dotted line indicates the automatic truncation (IT-C: Italy, Cascia; IT-P: Italy, Città della Pieve; IT-F: Italy, Pieve; IR-Gh: Iran, Ghaen; IR-T: Iran, Torbat; IR-Go: Iran, Gonabad). 
The whole dataset was finally used to build the dendrogram obtained with the Pearson's correlation matrix (Fig. 3). Three main groups (as underlined by the dotted line which represents the automatic truncation) could be identified. The group of saffron from Iran was homogeneous and well distinguished by the rest of the samples that clustered in two different groups, with saffron from Cascia clearly distinct from the rest of the Italian samples.

\section{Conclusion}

HPLC and PTR-TOF-MS analyses were performed to characterize saffron samples of different geographical origin. A higher content of total crocins (especially trans-crocin 4 and trans-crocin 3) is highlighted in saffron from Italy. HPLC analysis shows also Italian saffron to be richer in safranal (especially Cascia and Città della Pieve); this result is confirmed analyzing the intensity of the raw signal generated by PTR-TOF-MS approach.

The origin of the samples cannot be established using only the fast PTR-MS method, while the use of PCA applied to the whole dataset, including data from HPLC analysis, underlined the existence of groups, helping to better distinguish the geographical origin of each sample and pointing out safranal and isophorone to be the most informative compounds, together with picrocrocin.

\section{Acknowledgments}

The authors acknowledge Ente Cassa di Risparmio di Firenze (Project VOLATOM) and the Regione Toscana "PRAF 2012-2015 MISURA 1.2 e)" program (Project VOLATOSCA).

\section{References}

Alonso, G. L., Salinas, M., Garijo, J., \& Sanchez-Fernandez, M. A. (2001). Composition of crocins and picrocrocin from Spanish saffron (Crocus sativus L.). Journal of Food Quality, 24, 219-233.

Anastasaki, E., Kanalis, C., Pappas, C., Maggi, L., Del Campo, C. P., Carmona, M., et al. (2009). Geographic differentiation of saffron by GC-MS/FID and chemometrics. European Food Research and Technology, 229, 899-905.

Bolandi, M., \& Ghoddusi, H. B. (2006). Flavour and colour changes during processing and storage of saffron (Crocus sativus L.). Developments in Food Science, 42, 323-326.

Boschetti, A., Biasioli, F., van Opbergen, M., Warneke, C., Jordan, A., Holzinger, R. et al. (1999). PTR-MS real time monitoring of the emission of volatile organic compounds during postharvest aging of berryfruit. Postharvest Biology and Technology, 17, 143-151.

Caballero-Ortega, H., Pereda-Miranda, R., \& Abdullaev, F. I. (2007). HPLC quantification of major active components from 11 different saffron (Crocus sativus L.) sources. Food Chemistry, 100, 1127-1131.

Cappellin, L., Biasioli, F., Fabris, A., Schuhfried, E., Soukoulis, C., Tilmann, D. M., et al (2010). Improved mass accuracy in PTR-TOF-MS: another step towards better compound identification in PTR-MS. International Journal of Mass Spectrometry, 290, 60-63.

Carmon, M., Martínez, J., Zalacain, A., Rodríguez-Méndez, M. L., de Saja, J. A., \& Alonso, G. L. (2006). Analysis of saffron volatile fraction by TD-GC-MS and enose. European Food Research and Technology, 223, 96-101.

Carmona, M., Sánchez, A. M., Ferreres, F., Zalacain, A., Tomás-Barberán, F., \& Alonso L. G. (2007). Identification of the flavonoid fraction in saffron spice by LC/DAD/ MS/MS: Comparative study of samples from different geographic origins. Food Chemistry, 100, 445-450.

Carmona, M., Zalacain, A., Pardo, J. E., Loäpez, E., Alvarruiz, A., \& Alonso, G. L. (2005) Influence of different drying and aging conditions on saffron constituents. Journal of Agricultural and Food Chemistry, 53, 3974-3979.

D’Auria, M., Mauriello, G., Racioppi, R., \& Rana, G. L. (2006). Use of SPME-GC-MS in the study of time evolution of the constituents of saffron aroma: Modifications of the composition during storage. Journal of Chromatographic Science, 44, 18-21.

Del Campo, C. P., Carmona, M., Maggi, L., Kanakis, C. D., Anastasaki, E. G., Tarantilis, P. A., et al. (2010). Picrocrocin content and quality categories in different (345) worldwide samples of saffron (Crocus sativus L.). Journal of Agricultural and Food Chemistry, 58, 1305-1312.

Diskin, A. M., Wang, T., Smith, D., \& Španěl, P. (2002). A selected ion flow tube (SIFT), study of the reactions of $\mathrm{H}_{3} \mathrm{O}^{+}, \mathrm{NO}^{+}$and $\mathrm{O}_{2}^{+}$ions with a series of alkenes; in support of SIFT-MS. International Journal of Mass Spectrometry, 218, 87-101.

Fujii, T., Selvin, P. C., Sablier, M., \& Iwase, K. (2001). Lithium ion attachment mass spectrometry for online analysis of trace components in air: Direct introduction. International Journal of Mass Spectrometry, 209, 39-45.

Ghorbani, M. (2008). The efficiency of saffron's marketing channel in Iran. World Applied Sciences Journal, 4, 523-527.
Jalali-Heravi, M., Parastar, H., \& Ebrahimi-Najafabadi, H. (2010). Self-modeling curve resolution techniques applied to comparative analysis of volatile compounds of Iranian saffron from different regions. Analytica Chimica Acta, 662, 143-154.

Jardine, K., Abrell, L., Kurc, S. A., Huxman, T., Ortega, J., \& Guenther, A. (2010). Volatile organic compound emissions from Larrea tridentata (creosotebush). Atmospheric Chemistry and Physics, 10, 12191-12206.

Lage, M., \& Cantrell, C. L. (2009). Quantification of saffron (Crocus sativus L.) metabolites crocins, picrocrocins and safranal for quality determination of the spice grown under different environmental Moroccan conditions. Scientia Horticulturae, 121, 366-373.

Li, N., Lin, G., Kwan, Y. W., \& Min, Z. D. (1999). Simultaneous quantification of five major biologically active ingredients of saffron by high-performance liquid chromatography. Journal of Chromatography A, 849, 349-355.

Loskutov, A. V., Beninger, C. W., Hosfield, G. L., \& Sink, K. C. (2000). Development of an improved procedure for extraction and quantitation of safranal in stigmas of Crocus sativus L. using high performance liquid chromatography. Food Chemistry, 69, 87-95.

Lozano, P., Castellar, M. R., Simancas, M. J., \& Iborra, J. L. (1999). Quantitative highperformance liquid chromatographic method to analyse commercial saffron (Crocus sativus L.) products. Journal of Chromatography A, 830, 477-483.

Lozano, P., Delgado, D., Gomez, D., Rubio, M., \& Iborra, J. L. (2000). A non-destructive method to determine the safranal content of saffron (Crocus sativus L.) by supercritical carbon dioxide extraction combined with high performance liquid chromatography and gas chromatography. Journal of Biochemical and Biophysical Methods, 43, 367-378.

Macchia, M., Ceccarini, L., Molfetta, I. Cioni, P. L. \& Flamini, G. (2013). Studies on saffron (Crocus sativus L.) from Tuscan Maremma (Italy): effects of geographical origin, cultivation environment and drying method on volatile emission. Journal of Food Science and Technology, 48, 2370-2375.

Maggi, L., Carmona, M., Del Campo, C. P., Kanakis, C. D., Anastasaki, E., Tarantilis, P. A., et al. (2009). Worldwide market screening of saffron volatile composition. Journal of Agricultural and Food Chemistry, 89, 1950-1954.

Maggi, L., Carmona, M., Zalacain, A., Kanakis, C. D., Anastasaki, E., Tarantilis, P. A., et al. (2010). Changes in saffron volatile profile according to its storage time. Food Research International, 43, 1329-1334.

Mancuso, S., Taiti, C., Bazihizina, N., Costa, C., Menesatti, P., Giagnoni, L., et al. (2015). Soil volatile analysis by proton transfer reaction-time of flight mass spectrometry (PTR-TOF-MS). Applied Soil Ecology, 86, 182-191.

Masi, E., Romani, A., Pandolfi, C., Heimler, D., \& Mancuso, S. (2014). PTR-TOF-MS analysis of volatile compounds in olive fruits. Journal of the Science of Food and Agriculture. http://dx.doi.org/10.1002/jsfa.6837.

Mayr, D., Märk, T., Lindinger, W., Brevard, H., \& Yeretzian, C. (2003). Breath-bybreath analysis of banana aroma by proton transfer reaction mass spectrometry. International Journal of Mass Spectrometry, 223, 743-756.

Pfander, H., \& Rychener, M. (1982). Separation of crocetin glycosyl esters by highperformance liquid chromatography. Journal of Chromatography A, 234, 443-447.

Pujimulyani, D., Raharjo, S., Marsono, Y., \& Santoso, U. (2013). The effect of size reduction and preparation duration on the antioxidant activity of white saffron (Curcuma mangga Val.). Journal of Food and Pharmaceutical Sciences, 1, 18-21.

Rios, J. L., Recio, M. C., Giner, R. M., \& Manez, S. (1996). An update review of saffron and its active constituents. Phytotherapy Research, 10, 189-193.

Soukoulis, C., Cappellin, L., Aprea, E., Costa, F., Viola, R., Märk, T. D., et al. (2013). PTRTOF-MS, a novel, rapid, high sensitive and non-invasive tool to monitor volatile compound release during fruit post-harvest storage: The case study of apple ripening. Food and Bioprocess Technology, 6, 2831-2843.

Taiti, C., Costa, C., Menesatti, P., Comparini, D., Bazihizina, N., Azzarello, E., Masi, E., \& Mancuso, S. (2014). Class-modeling approach to PTR-TOFMS data: A peppers case study. Journal of the Science of Food and Agriculture. http://dx.doi.org/ $10.1002 /$ jsfa.6761.

Taiti Taiti, C., Costa, C., Menesatti, P., Caparrotta, S., Bazihizina, N., Azzarello, E., Petrucci, W., Masi, E., \& Giordani, E. (2015). Use of volatile organic compounds and physicochemical parameters for monitoring the post-harvest ripening of imported tropical fruits. European Food Research and Technology. http:// dx.doi.org/10.1007/s00217-015-2438-6.

Tarantilis, P. A., \& Polissiou, M. G. (1997). Isolation and identification of the aroma components from saffron (Crocus sativus). Journal of Agricultural and Food Chemistry, 45, 459-462.

Tarantilis, P. A., Polissiou, M., \& Manfait, M. (1994). Separation of picrocrocin, cistrans-crocins and safranal of saffron using high-performance liquid chromatography with photodiode-array detection. Journal of Chromatography A, 664, 55-61.

Tarantilis, P. A., Tsoupras, G., \& Polissiou, M. (1995). Determination of saffron (Crocus sativus L.) components in crude plant extract using high-performance liquid chromatography-UV-visible photodiode-array detection-mass spectrometry. Journal of Chromatography A, 699, 107-118.

Vignolini, P., Heimler, D., Pinelli, P., Ieri, F., Sciullo, A., \& Romani, A. (2008). Characterization of by products of saffron (Crocus sativus L.) production. Natural Product Communications, 3, 1959-1962.

Wang, T., Španěl, P., \& Smith, D. (2004). A selected ion flow tube study of the reactions of $\mathrm{H}_{3} \mathrm{O}^{+}, \mathrm{NO}^{+}$and $\mathrm{O}_{2}^{+}$with some phenols, phenyl alcohols and cyclic carbonyl compounds in support of SIFT-MS and PTR-MS. International Journal of Mass Spectrometry, 239, 139-146.

Xi, L., \& Qian, Z. (2006). Pharmacological properties of crocetin and crocin (digentiobiosyl) ester of crocetin from saffron. Natural Product Communications, 1, 65-75. 